\title{
Recommendations to improve healthcare of neonates with respiratory insufficiency beneficiaries of Seguro Popular
}

\author{
Luis Jasso-Gutiérrez, MD, MSc,(') Luis Durán-Arenas, MD, PhD,(2) \\ Samuel Flores-Huerta, MD,(3) Gabriel Cortés-Gallo, MD.(4)
}

\section{Jasso-Gutiérrez L, Durán-Arenas L, \\ Flores-Huerta S, Cortés-Gallo G. Recommendations to improve healthcare of neonates with respiratory insufficiency beneficiaries of Seguro Popular. Salud Publica Mex 20I2;54 suppl I:S57-S64.}

\begin{abstract}
Objective. To evaluate the structure and processes of care of neonatal intensive care units (NICU) providing health care to neonates with respiratory insufficiency, and financed by Seguro Popular. Materials and Methods. A cross-sectional design was used; 2I NICU were included. Information was collected from four sources: Seguro Popular database, selfapplicable interviews to medical staff, structure and processes format, and reviews of clinical charts. Variables: structure, processes of care, drug supplies, training, and neonates' clinical conditions. Results. The analysis of the database included 9679 newborns. The respiratory disorders were transitory tachypnea, non-specific respiratory insufficiency, respiratory distress syndrome, (RDS) perinatal asphyxia, and meconium aspiration syndrome. $90 \%$ of NICU'S directors considered that drug supply was good, whereas only $16 \%$ of neonatologist had this opinion. $58.5 \%$ of neonates with RDS had $<37$ gestation weeks. $34.2 \%$ with RDS were prescribed alveolar surfactant; $51 \%$ received dosages above recommended standards. Conclusions. Recommendations to improve infrastructure and care processes are issued.
\end{abstract}

Key words: neonate respiratory insufficiency; respiratory distress syndrome; health insurance; neonatal intensive care unit; quality of care; neonatal mortality; Mexico
Jasso-Gutiérrez L, Durán-Arenas L,

Flores-Huerta S, Cortés-Gallo G.

Recomendaciones para mejorar el cuidado

de la salud de neonatos con insuficiencia respiratoria

beneficiarios del Seguro Popular.

Salud Publica Mex 20 I 2;54 supl I:S57-S64.

\section{Resumen}

Objetivo. Evaluar infraestructura y procesos en las unidades de cuidado intensivo neonatal (NICU) de tercer nivel que atienden neonatos con insuficiencia respiratoria financiados por el Seguro Popular. Material y métodos. Formatos validados de: infraestructura; procesos de atención; surtimiento de medicamentos; opinión de médicos y revisión de expedientes clínicos. Resultados. Taquipnea transitoria, insuficiencia respiratoria no especificada y síndrome de dificultad respiratoria (RDS), fueron los más frecuentes. Algunas NICU no tenían neonatólogos o residentes. El surtimiento de medicamentos fue bueno en opinión de $90 \%$ de los jefes y de $16 \%$ de médicos del staff. El $58.5 \%$ de neonatos con RDS tuvieron $\leq 37$ semanas de gestación. Recibieron surfactante $34.2 \%$ de neonatos con RDS y en $51 \%$ la dosis fue superior a la recomendada. La condición al arribar a la NICU fue grave en $89.6 \%$. La mortalidad por RDS fue I4\%. Conclusiones. Se emiten recomendaciones de mejora en aspectos de infraestructura y de procesos.

Palabras clave: insuficiencia respiratoria del neonato; síndrome de dificultad respiratoria; unidad de cuidado intensivo neonatal; calidad de atención; mortalidad neonatal; México

(I) Departamento de Evaluación y Análisis de Medicamentos, Hospital Infantil de México Federico Gómez. México.

(2) Centro de Estudios Económicos y Sociales en Salud, Hospital Infantil de México Federico Gómez. México.

(3) Departamento de Investigación en Salud Comunitaria, Hospital Infantil de México Federico Gómez. México.

(4) Dirección del Seguro Médico para una Nueva Generación, Secretaría de Salud. México. 
$\mathrm{T}$ he neonatal mortality rate (NMR) is declining gradually in the world; nonetheless, it accounts for $48 \%$ of deaths among children under 5 years of age. Differences exist among regions and countries. African countries, China and India have the highest NMR figures. ${ }^{1}$ In Mexico, from 1990 to 2006, the neonatal mortality rate in the population cared for at the Mexican Institute for Social Security (Instituto Mexicano del Seguro Social, IMSS), which is an institution providing care to 48 million people, declined from 12.47 per 1000 live births to $8.70 .^{2}$ These rates are lower with respect to those reported by the total of institutions that integrate the Mexican health sector. From 1980 to 2005 NMR declined from 15.7 to 10.3 per 1000 live births among the people that do not have access to social security services in Mexico. ${ }^{3}$

Respiratory disorders are the leading cause of early mortality (0-7 days of age). In descending order the top six causes of death are respiratory distress syndrome, asphyxia at birth, meconium aspiration syndrome, other respiratory problems, intrauterine hypoxia, and congenital pneumonia. ${ }^{2}$

To maintain the declining trend of neonatal and infant mortality in Mexico, the federal government implemented the program Medical Insurance for a New Generation (Seguro Médico para una Nueva Generación, SMNG) as part of the System for Social Protection of Health (Sistema de Protección Social en Salud) commonly known as Seguro Popular. SMNG finances primary and secondary health care services for children born since December 2006. Seguro Popular also has under its purview the Fund for Protection against Catastrophic Expenditures (Fondo de Protección contra Gastos Catastróficos, FPGC), which finances health care for high-cost, low-prevalence conditions. FPGC funds a large group of respiratory health conditions for newborns who require care in neonatal intensive care units (NICU), ${ }^{4}$ such as respiratory distress syndrome (RDS), meconium aspiration syndrome (MAS), transitory tachypnea of newborn (TTN), perinatal asphyxia (PERASPH) and non-specific respiratory insufficiency (NSRF). ${ }^{5}$

Periodically, the social programs of the federal government, such as FPGC and SMNG should be evaluated by external organizations from the government. ${ }^{6} \mathrm{SMNG}$ directorate signed an agreement with Hospital Infantil de México Federico Gómez (HIMFG) to run the external evaluation of the component of newborn's respiratory diseases covered by the FPGC.

According to the requirements of the SMNG directorate, this evaluative study focused on the analysis and evaluation of the clinical information of neonates admitted to NICUs with any of the above-mentioned respiratory diagnosis.
The evaluation comprised epidemiological and medical aspects, infrastructure available, medical personnel, processes of care, and availability and distribution of necessary drugs.

This paper describes the main findings of this evaluation, which in turn served to support some recommendations to improve the clinical and managerial processes and the quality of care that these children receive.

\section{Materials and methods}

Design: this evaluative study comprised four methodologies:

1. Descriptive analysis of the SMNG database.

2. Description of the characteristics of the infrastructure, supplies and personnel in the NICUs

3. Self-applicable questionnaire for pediatricians and neonatologist working at NICUs

4. Review of the clinical charts of children with respiratory distress syndrome

Study site: The study took place in 21 NICUs located in 21 hospitals from 15 states of Mexico. The sampling design was probabilistic, polietapic and stratified.

The scientific committee and the ethics review board of Hospital Infantil de Mexico Federico Gómez evaluated and authorized the study protocol.

\section{Descriptive analysis of the SMNG database}

The SMNG directorate provided to the researchers the 2008 database of the newborns admitted to a NICU due to respiratory failure. The database contained the following information: name of the child, SMNG membership number, state were the child received treatment, date of birth, gender, date of admission, age at admission, gestational age in weeks, diagnosis and comorbidity.

The database also had the name of the attending physician, of the person who validated the information at the state, and the date of the validation. The database did not register the health status of the child at discharge (health improvement or death) or the type of treatment (medical or surgical).

The five respiratory conditions in the database were RDS, MAS, TTN, PERASPH, and NSRF. The diagnoses were classified according to the International Classification of Diseases version 10 (ICD-10). The codes were P05.1, P05.2, P05.9, P070, P07.39, and P25 to P37 and P22, P23 and P28. 


\section{Description of the characteristics of the infrastructure, supplies and personnel at the NICUs}

A data collection instrument to gather the information about the infrastructure, supplies and personnel was designed and validated. The instrument was designed and validated by four neonatologists. The information to fill out the questionnaire was collected by a previously trained interviewer, who did a visual inspection of the NICU and interviewed the head of the NICU or a representative. The variables included capacity to admit newborns, number of annual admissions, number of admissions due to respiratory distress syndrome, number of incubators, heaters, portable incubators, infusion pumps, ventilators, availability of neonatologists during the three shifts (morning, evening and night), availability of pediatricians, nurses and residents. The NICUs were classified in highest capacity and lowest capacity in accordance with available infrastructure, number of beds and personnel.

\section{Self-applicable questionnaire for pediatricians and neonatologist working at NICUs}

The questionnaire was designed and validated by four neonatologists. The respiratory distress syndrome (RDS) was considered as a tracer condition given that it is representative of the complex care that NICUs provide. The questionnaire collected information about the diagnosis and treatment of RDS, such as availability of explicit protocols for endotraqueal intubation, assisted ventilation and alveolar surfactant. It also gathered the opinion of attending doctor about availability of alveolar surfactant, dopamine and dobutamine; their perception about the quality of care at the NICUs where they were working and about the mortality rate of newborns with RDS.

\section{Review of the clinical charts of children with respiratory distress syndrome}

A representative sample of 268 clinical charts of infants with RDS treated in selected NICUs was estimated. A data collection instrument was designed to collect the information. Similar to the other instruments, this was designed and validated by four neonatologists. The instrument gathered information to learn about the history of antenatal care, gestational age and birth weight, APGAR score, resuscitation maneuvers, gasometry and x-ray exams, administration of alveolar surfactant, opportunity of referral, use of mobile incubators, condi- tions of the newborns at admission, number of days with assisted ventilation, comorbidity and mortality rate.

All included NICUs had been accredited and licensed by the General Directorate of Quality of the Ministry of Health. The sample size of the NICUs was 21 out of the registered 48 NICUs with Seguro Popular. The sampling design was based on a probabilistic process; NICUs in fifteen states were included in the study.

\section{Results}

\section{Descriptive analysis of the SMNG database}

The original database had 11029 newborns out of which 1350 were not included in the analysis because their information was incomplete. The final analysis included 9679 newborns.

Table I shows number of newborns with neonatal respiratory disorders cared for at neonatal intensive care units in the 32 Mexican states. At national level, the distribution of these respiratory disorders was transitory tachypnea of the newborn (29.8\%), non-specific respiratory insufficiency $(28.5 \%)$, respiratory distress syndrome $(25.5 \%)$, perinatal asphyxia (10.7\%) and meconium aspiration syndrome (5.5\%). There was a wide variability among the states regarding the distribution of each of these conditions. States such as Jalisco, Guanajuato, Mexico and with no specific identifiable pattern among states and type of respiratory disorder.

Table II illustrates the distribution of neonatal respiratory disorders by postnatal and gestational age of newborns admitted to NICUs. The table shows that about $50 \%$ of newborns were admitted during the first 24 hours of age, whereas $20 \%$ of admissions happened at 11 or more days of age. Regarding gestational age, it was observed that among the neonates with 37 weeks or less at birth, the most common respiratory disorders were RDS (65.6\%) NSRF (70.7\%) and NSRF (98.5\%). These are cumulative percentages. Whereas among those with $>38$ weeks of gestation, perinatal asphyxia was diagnosed in $65.4 \%$ and AMS in $84.6 \%$.

Table III analyses the infrastructure, supplies and personnel of 21 NICUs. The analysis divided the NICUs in high $(n=9)$ and low capacity $(n=12)$ facilities. Low capacity NICUs predominated, although the provision of equipment and personnel was proportional to their capacity. Low capacity NICUs did not have portable incubators, fewer pediatricians, neonatologists and pediatrics residents.

The department heads of the NICU considered as appropriate the supply of necessary drugs to care for infants with respiratory distress. The percentage of supply for furosemide, digoxin, phenytoin and broad-spectrum 
Table I

StATE DISTRIBUTION OF THE NUMBER OF NEWBORNS WITH NEONATAL RESPIRATORY DISORDERS CARED FOR AT NEONATAL INTENSIVE CARE UNITS

\begin{tabular}{|c|c|c|c|c|c|c|}
\hline State & $\begin{array}{c}\text { Transitory tachypnea of } \\
\text { the newborn }\end{array}$ & $\begin{array}{l}\text { Non-Specific respiratory } \\
\text { insufficiency }\end{array}$ & $\begin{array}{l}\text { Respiratory distress } \\
\text { syndrome }\end{array}$ & $\begin{array}{l}\text { Perinatal } \\
\text { asphyxia }\end{array}$ & $\begin{array}{l}\text { Meconium aspiration } \\
\text { syndrome }\end{array}$ & Total \\
\hline & $\begin{array}{c}2883 \\
\%\end{array}$ & $\begin{array}{c}2758 \\
\%\end{array}$ & $\begin{array}{c}2471 \\
\%\end{array}$ & $\begin{array}{l}1036 \\
\%\end{array}$ & $\begin{array}{c}531 \\
\%\end{array}$ & $\begin{array}{c}9679 \\
\%\end{array}$ \\
\hline Aguascalientes & 6.1 & 11.4 & 5.5 & 7.2 & 4.7 & 7.2 \\
\hline Baja California & 2.9 & 0.9 & 2.3 & 0.7 & 0.4 & 1.8 \\
\hline Baja California Sur & ND & ND & ND & ND & ND & ND \\
\hline Campeche & 0.6 & 0.3 & 0.1 & 0.2 & 4.3 & 0.6 \\
\hline Chiapas & 0.9 & 6.0 & 2.8 & 11.5 & 10.0 & 4.5 \\
\hline Chihuahua & 2.2 & 0.7 & 5.5 & 2.3 & 2.3 & 2.7 \\
\hline Coahuila & 0.1 & 0.2 & 1.1 & 0.0 & 0.4 & 0.4 \\
\hline Colima & 0.6 & 1.5 & 1.3 & 0.0 & 1.1 & 1.0 \\
\hline Distrito Federal & 10.1 & 8.6 & 3.2 & 2.0 & 1.5 & 7.0 \\
\hline Durango & 5.4 & 2.1 & 3.7 & 11.0 & 7.3 & 4.8 \\
\hline Guanajuato & 6.5 & 10.9 & 7.7 & 5.9 & 5.1 & 7.8 \\
\hline Guerrero & 2.3 & 4.2 & 5.9 & 6.6 & 5.3 & 4.4 \\
\hline Hidalgo & 0.4 & 0.3 & 3.0 & 1.0 & 1.5 & 1.2 \\
\hline Jalisco & 21.3 & 12.1 & 9.9 & 8.0 & 6.2 & 13.4 \\
\hline Mexico & 6.1 & 10.3 & 7.2 & 4.2 & 8.7 & 7.5 \\
\hline Michoacán & 0.1 & I.I & 1.9 & 0.0 & 0.0 & 0.8 \\
\hline Morelos & 0.5 & 1.4 & 1.3 & 1.6 & 2.6 & 1.2 \\
\hline Nayarit & 6.8 & 0.1 & 3.6 & 2.2 & 0.9 & 3.3 \\
\hline Nuevo Leon & 0.0 & 1.3 & 5.3 & 0.5 & 0.8 & 1.9 \\
\hline Oaxaca & 0.5 & 0.7 & 1.3 & 2.3 & 2.3 & 1.1 \\
\hline Puebla & 1.5 & 7.2 & 5.6 & 2.2 & 5.1 & 4.3 \\
\hline Queretaro & 4.9 & 1.7 & 2.6 & 6.8 & 3.8 & 3.6 \\
\hline Quintana Roo & 0.1 & 0.0 & -- & 0.0 & 0.0 & 0.0 \\
\hline San Luis Potosi & 1.9 & 0.9 & 0.9 & 1.6 & 3.0 & 1.4 \\
\hline Sinaloa & 4.7 & 0.3 & 2.1 & 0.9 & 2.1 & 2.3 \\
\hline Sonora & 1.7 & 2.1 & 0.0 & 0.1 & 0.2 & 1.0 \\
\hline Tabasco & 6.3 & 0.4 & 2.6 & 10.7 & 6.0 & 4.2 \\
\hline Tamaulipas & 2.2 & 0.5 & 7.4 & 1.9 & 6.4 & 3.3 \\
\hline Tlaxcala & 0.3 & I.I & 0.8 & 1.0 & 0.2 & 0.7 \\
\hline Veracruz & 2.0 & 0.9 & 3.0 & 3.0 & 2.6 & 2.1 \\
\hline Yucatan & 0.8 & 2.9 & & 2.9 & 2.1 & 1.5 \\
\hline Zacatecas & 0.4 & 7.8 & 2.4 & 1.7 & 3.2 & 3.0 \\
\hline
\end{tabular}

Source: 2009 evaluation of the Medical Insurance of the New Generation, Mexico $\mathrm{ND}=$ No data

antibiotics was 100\%; for dopamine, adrenaline and diazepam was $95 \%$. Other reported drugs were alveolar surfactant $81 \%$, amphotericin B $66.7 \%$, ganciclovir $47.6 \%$, indomethacin $42.9 \%$, phenobarbital $33.3 \%$ and prostaglandin E1 23.6\%.

Table IV shows the answers of the self-assessment survey that 97 pediatricians or neonatologists working at the NICUS. All of them were working in the morning shift. Most of NICUs had explicit protocols for endotracheal intubation and mechanical assistance to start the ventilation. $99 \%$ of medical doctors had taken a course on cardiopulmonary resuscitation. Attending medical doctors considered as low the availability of drugs such as surfactant (14.5\%) dopamine (9.3\%) and dobutamine $(9.3 \%)$. None of the medical doctors considered that the frequency of pneumothorax was above $20 \%$. Only $16.5 \%$ of them considered as good or very good the quality of care of the NICUs, and $12.4 \%$ 
Table II

DISTRIBUTION OF NEONATAL RESPIRATORY DISORDERS BY POSTNATAL AND GESTATIONAL AGE OF THE NEONATES ADMITTED TO NEONATAL INTENSIVE CARE UNITS

\begin{tabular}{|c|c|c|c|c|c|c|c|c|c|c|}
\hline \multirow[b]{2}{*}{ Postnatal age (day } & \multicolumn{2}{|c|}{$\begin{array}{l}\text { Transitory achypnea } \\
\text { of the newborn }\end{array}$} & \multicolumn{2}{|c|}{$\begin{array}{c}\text { Non-specific respiratory } \\
\text { insufficiency }\end{array}$} & \multicolumn{2}{|c|}{$\begin{array}{l}\text { Respiratory distress } \\
\text { syndrome }\end{array}$} & \multicolumn{2}{|c|}{$\begin{array}{l}\text { Perinatal } \\
\text { asphyxia }\end{array}$} & \multicolumn{2}{|c|}{$\begin{array}{l}\text { Aspiration meconium } \\
\text { syndrome }\end{array}$} \\
\hline & $n$ & $\%$ & $n$ & $\%$ & $n$ & $\%$ & $n$ & $\%$ & $n$ & $\%$ \\
\hline$\leq I$ day & 1375 & 47.7 & 1486 & 53.9 & 1407 & 56.9 & 604 & 58.3 & 310 & 58.6 \\
\hline 2-3 days & 312 & 10.8 & 238 & 8.6 & 120 & 4.9 & 76 & 7.3 & 36 & 6.7 \\
\hline 4-6 days & 349 & 12.1 & 175 & 6.3 & 84 & 3.4 & 94 & 9.1 & 50 & 9.4 \\
\hline $7-10$ days & 239 & 8.3 & 169 & 6.1 & 111 & 4.5 & 62 & 6.0 & 37 & 6.9 \\
\hline$\geq$ II days & 608 & 21.1 & 690 & 25.0 & 749 & 30.3 & 200 & 19.3 & 98 & 18.4 \\
\hline Total & 2883 & 100 & 2758 & 100 & $247 \mid$ & 100 & 1036 & 100 & 531 & 100 \\
\hline \multicolumn{11}{|c|}{ Gestational age (weeks) } \\
\hline $24-28$ & 12 & 0.4 & 42 & 1.5 & 266 & 10.8 & 17 & 1.6 & 0 & 0.0 \\
\hline $29-32$ & 182 & 6.3 & 297 & 10.8 & 913 & 36.9 & 52 & 5.0 & 9 & 1.7 \\
\hline $33-37$ & 1698 & 58.9 & 1610 & 58.4 & 1255 & 50.8 & 290 & 28.0 & 73 & 13.7 \\
\hline $38-41$ & 915 & 31.7 & 809 & 29.3 & 34 & 1.4 & 635 & 61.3 & 363 & 68.5 \\
\hline$\geq 42$ & 76 & 2.6 & 0 & 0.0 & 3 & 0.1 & 42 & 4.1 & 86 & 16.1 \\
\hline Total & 2883 & 100 & 2758 & 100 & 2471 & 100 & 1036 & 100 & 531 & 100.0 \\
\hline
\end{tabular}

Source: 2009 evaluation of the Medical Insurance of the New Generation, Mexico

Table III

ANALYSIS OF THE NICUs' STRUCtURE: PERSONNEL, EQUIPMENT AND SUPPLIES

\begin{tabular}{|c|c|c|c|c|c|}
\hline \multirow{2}{*}{ Variables } & \multicolumn{2}{|c|}{$\begin{array}{l}\text { High capacity NICU } \\
(n=9)\end{array}$} & \multicolumn{3}{|c|}{$\begin{array}{c}\text { Low capacity NICU } \\
(n=12)\end{array}$} \\
\hline & Number & $\%$ & Number & $\%$ & ND \\
\hline Maximum capacity to admit children & 12 to 28 & 42.8 & I to II & 57.2 & \\
\hline Annual admissions due to different causes & $|2|$ to 800 & 30.4 & I a 120 & 60.6 & 8.7 \\
\hline Annual admissions due to respiratory distress syndrome & $5 \mathrm{I}$ to 250 & 26.0 & I to 50 & 69.9 & \\
\hline Incubators & 7 to 23 & 33.3 & I to 6 & 52.4 & 14.3 \\
\hline Radiant heaters & 7 to 15 & 23.8 & I to 6 & 76.2 & \\
\hline Neonatal transport incubator & ND & 95.2 & ND & 90.0 & \\
\hline Infusion pumps & 18 to 21 & 33.3 & I to 17 & 66.6 & \\
\hline Neonatal ventilators & 15 to 20 & 33.3 & I to II & 66.7 & \\
\hline Presence of red car & ND & 100.0 & ND & 100.0 & \\
\hline Neonatologists in three shifts (morning, evening and night) & 3 to 8 & 52.4 & I to 2 & 43.3 & 14.3 \\
\hline Pediatricians (non specialized in neonatology) in the three shifts & 4 to 13 & 33.3 & I to 3 & 38.1 & \\
\hline Nurses on all three shifts & 7 to 35 & 19.0 & I to 6 & 81.0 & \\
\hline Pediatrics residents during the morning shift & NA & 77 & None & 0.0 & \\
\hline
\end{tabular}

considered that the mortality rate of infants with RDS was $30 \%$ or higher.

Table V describes the analysis of 268 clinical charts of newborns admitted to neonatal intensive care units due to respiratory distress syndrome. The analysis shows that $77 \%$ of the mothers attended to prenatal care, and $54 \%$ of them began since the first trimester. $84.5 \%$ of newborns were premature and $78 \%$ had birth 
Table IV

ANSWERS OF MEDICAL DOCTORS WORKING IN NEONATAL INTENSIVE CARE UNITS ABOUT THE TREATMENT OF RESPIRATORY DISTRESS SYNDROME

Availability of explicit protocol for endotracheal intubation 94.8

Availability of explicit protocol to start assisted ventilation 92.8

Attendance to cardiopulmonary resuscitation course

99.0

Availability of a protocol for administering alveolar surfactant

86.6

If there is a protocol for administration of surfactant, compliance is good

75.0

Alveolar surfactant always and almost always is available at the neonatal intensive care unit

14.5

Dopamine always and almost always is available

9.3

Dobutamine always and almost always available

9.3

Frequency of pneumothorax over $20 \%$

0.0

The care provided at the NICUs is of good to very good quality

Mortality above $30 \%$ due to respiratory distress syndrome

16.5

12.4

Source: 2009 evaluation of the Medical Insurance of the New Generation, Mexico

Table V

ANALYSIS OF CLINICAL CHARTS OF NEWBORNS ADMITTED TO NEONATAL INTENSIVE CARE UNITS (NICUS) DUE TO RESPIRATORY DISTRESS SYNDROME

\begin{tabular}{|c|c|c|c|}
\hline \multirow{3}{*}{ Variables } & \multicolumn{2}{|c|}{$N=268$} & \multirow{3}{*}{$\begin{array}{c}\text { Data not } \\
\text { available } \\
\quad \%\end{array}$} \\
\hline & Yes & No & \\
\hline & $(\%)$ & $\%$ & \\
\hline History of prenatal care & 77.7 & 22.3 & - \\
\hline History of prenatal care since the first trimester & 54.2 & 45.8 & - \\
\hline Gestational age at birth $\leq 37$ weeks & 84.5 & 15.5 & - \\
\hline Birth weight $\leq 2500 \mathrm{~g}$ & 78.1 & 21.9 & - \\
\hline APGAR score at $5 \mathrm{~min} \leq 7$ & 19.4 & 80.6 & - \\
\hline $\begin{array}{l}\text { Resuscitation maneuvers or cardiopulmonary } \\
\text { resuscitation }\end{array}$ & 46.8 & 48.4 & 4.8 \\
\hline Endotracheal intubation at birth & 42.8 & 55.0 & 2.2 \\
\hline Arterial gasometry taken in $\leq 72$ hours after birth & 43.5 & 39.5 & 17.0 \\
\hline Chest $\mathrm{x}$-ray taken $\leq 72$ hours after birth & 77.0 & 14.0 & 9.0 \\
\hline $\begin{array}{l}\text { Administration of alveolar surfactant } \leq 72 \text { hours } \\
\text { after birth }\end{array}$ & 34.2 & 55.4 & 10.4 \\
\hline Referred to a NICU in a mobile incubator & 34.2 & 27.0 & 38.2 \\
\hline Duration of transportation to $\mathrm{NICU} \leq 120$ minutes & 29.5 & 0.9 & 69.6 \\
\hline $\begin{array}{l}\text { Severe or very severe condition of the newborn at } \\
\text { admission to NICU }\end{array}$ & 89.6 & 1.6 & 8.8 \\
\hline $\begin{array}{l}\text { Total days on assisted ventilation } \geq 30 \text { (with or } \\
\text { without assistance) }\end{array}$ & 3.5 & 77.7 & 18.8 \\
\hline Comorbidity due to septicemia & 46.9 & 53.1 & - \\
\hline Comorbidity due to necrotizing enterocolitis & I3.8 & 86.2 & - \\
\hline Comorbidity due to intracraneal bleeding & 8.5 & 91.5 & - \\
\hline Mortality rate in the NICU & 14.2 & 83.4 & 2.4 \\
\hline
\end{tabular}

Source: 2009 evaluation of the Medical Insurance of the New Generation, Mexico weight $\leq 2500$ g. $46.8 \%$ required resuscitation maneuvers at birth; $42.8 \%$ required endotracheal intubation. The alveolar surfactant was administered to $34.2 \%$ of newborns with RDS. Upon arrival to the NICU $89.6 \%$ had severe or very severe clinical conditions. The most common comorbidities in descending order were sepsis, necrotizing enterocolitis and intracranial hemorrhage. The mortality rate in this sample was $14.2 \%$.

\section{Discussion}

The four sources of information provided a comprehensive picture of the care that newborns receive at NICUs. The characteristics of the newborns at admission, available personnel, supplies and infrastructure, and the view of medical doctors provided valuable information.

The variability in the number of newborns with neonatal respiratory disorders among the states might be explainable. It was observed that the states of Jalisco, Guanajuato, Mexico, Aguascalientes and Mexico City had the highest number of cases of respiratory failure admitted to NICUs. This can be due to the size of the population affiliated with Seguro Popular, or the number of accredited NICUs in the states when compared with those accredited in other states. It would be advisable that future studies address in-depth these differences.

Among the five neonatal respiratory disorders, four of them are the leading causes of death in NICUs. Transitory tachypnea of the newborn has very low mortality rate. $^{2}$ This condition has a short length of stay and the necessary supplies for its treatment are not expensive, 
such as oxygen in the incubator or headgear, humidity and heat. ${ }^{8}$ It is advisable to remove this condition from the FPGC and to include it in within the conditions that SMNG covers. The cost of treatment for this condition is considerably lower that the cost for the other four respiratory disorders. This does not mean that the newborns with TTN will not be admitted to NICUs or receive the same quality. RDS, NSRF and perinatal asphyxia are more severe conditions, with longer length of stay. These conditions require highly qualified health personnel, and expensive supplies for its treatment, such as drugs, intravenous solutions, equipment, mechanical ventilation and so forth. The actual costs of these conditions are not fully known. It is advisable to estimate the costs of their treatment.

Admission of the newborn to the NICU within the first 24 hours after birth increases the possibility of reducing mortality and neurological sequels. Fifty percent of newborns in this sample did not have this opportunity because they were admitted 24 hours after birth. An important flaw of FPGC registries is the lack of information about the health outcomes of the newborn at discharge. It was not possible to learn whether the newborn survived or died. Including this information is absolutely necessary given its importance for decisionmaking. To evaluate the potential sequels of these respiratory conditions, it is advisable to run follow-up studies until these children reach 5 or 6 years of age. ${ }^{9}$

The respiratory distress syndrome appears less often in children born after 36 weeks of gestation; nonetheless, this condition was more frequent than expected in this study. A possible explanation was that the newborns with this condition were administered alveolar surfactant more often. An opposite situation happened with premature newborns in which the main problem is the low synthesis of alveolar surfactant. ${ }^{10,11}$ Another possible explanation is that the gestational age of the newborns was miscalculated or the diagnosis of RDS was not accurate and the newborns had respiratory failure due to conditions other than RDS. These findings support the recommendation to identify in all accredited NICUs, the reliability and validity of the RDS diagnoses. As mentioned above, 77 cases with diagnosis of RDS were not included in this analysis due to incomplete clinical, laboratory and / or radiology information to confirm such diagnosis.

Evaluating the characteristics of the structure of the NICUs is a complex matter. An article reported that 35 out of the 50 states in the United States of America had wide variations regarding the capability of response of the NICU. ${ }^{12}$ The variation was from level of care II to level of care VI.

Three criteria are required to fulfill the national regulatory norms. There were 24 states that only were able to fulfill one criterion and nine more states were able to fulfill one or more of these regulatory criteria. Twentyfive states fulfilled the functional criteria that included characteristics of the population, capability to provide respiratory care and neonatal cardiac surgery. Thirteen states were considered as having the highest medical care level (level VI) because the "utilization" criteria were considered. These criteria include capability, turnover and percentage of occupancy. The study concluded that in the US there is a wide variability of care.

In the present study, the set of NICU showed wide variations in the different levels of care. The structure of most of NICUs was appropriate in terms of the number of intensive care beds, human and material resources. This situation was confirmed regarding the proportion of neonatologists, pediatricians and nurses working in the three working shifts. However, given that $33.3 \%$ of NICU did not have residents, it is advisable to review the accreditation criteria.

All NICU had a nosocomial infections committee, although this study had the limitation of not quantifying the mortality rates due to nosocomial infections or checking whether the committees were actually working. In this same context, drug supply to care for neonates with RDS is another relevant aspect of the evaluation of the structure. ${ }^{13}$ The differences in the alveolar surfactant supply mentioned by the chief of service $(>90 \%)$ and by the attendants $(<40 \%)$ suggest the need to implement efficient supply strategies that should be monitored periodically.

The NICU had specific protocols for ventilator support, endotracheal intubation and most of medical doctors were trained on cardiopulmonary resuscitation. Nonetheless, only $78.4 \%$ were knowledgeable about the management and functioning of a neonatal ventilator. This finding should prompt the training of those who lack of this knowledge in all accredited NICU. The frequencies reported of bronchopulmonary dysplasia and pneumothorax due to RDS was lower than usual figures. ${ }^{14,15}$ It is possible to assume that these frequencies were underestimated, considering that the neonates who were on mechanical ventilation support had more severe conditions.

If measuring the quality of care of the NICUs were possible through using an indirect method and a single parameter such as the opinion of the attendants working there, the conclusion would be that the quality of care was low. This in part is supported by the finding that $14 \%$ of NICU did not have a standardized protocol to administer alveolar surfactant, and this medication was used in a low percentage of neonates with SRD, and in whom it was prescribed, $51 \%$ of cases received higher doses than recommended. It is pertinent to include these 
topics in future evaluations and interventions aimed at solving these deficiencies.

The review of clinical records showed that $41 \%$ of neonates with RDS did not require mechanical ventilation support. This finding, along with the low mortality rate of neonates with RDS allows assuming that some of these neonates did not have such condition. This is contrary to other reports in which RDS has high mortality rates. It is possible that these neonates would have another condition such as TTN. On one hand, the mortality rate of these neonates should have been higher, because $66 \%$ were not transported in mobile incubators; the time elapsed for transportation was longer than 2 hours in $70.5 \%$ of cases; $89.6 \%$ were considered as severely ill when admitted to the NICU, and $46.9 \%$ had septicemia. On the other hand, $61 \%$ of neonates were born in the same hospital in which the NICU was, and $39.6 \%$ were transported appropriately. It is advisable to review in depth this issues in future evaluations.

This evaluation is providing a preliminary picture of the quality of care at NICU that the SMNG funds. It is advisable to evaluate in depth the structure, process and health outcomes of these facilities. Analyzing incomplete or erroneous information are common problems that evaluators face when evaluating the effectiveness of NICU. Better-designed evaluations can identify with greater objectivity the deficiencies of the NICU, which in turn would result in sound recommendations to improve their performance that in turn would help in improving health outcomes of the neonates.

Declaration of conflict of interests. The authors declare that they have no conflict of interests.

\section{References}

I. Black RR, Cousens S, Johnson HL, Lawn JE, Rudan I, Bassani DG, et al. global, regional, and national causes of child mortality in 2008: a systematic analysis. Lancet 2010; 375:1969-1987.
2. Jasso GL. Mortalidad Perinatal y Neonatal . En: Jasso GL. Neonatología práctica. 7a. Edición. México, El Manual Moderno, 2008:1-5.

3. Perdigón-Villaseñor G, Fernández-Cantón SB. La mortalidad neonatal y postneonatal en México, 1980-2005. Bol Med Hosp Infant Méx. 2008; 65: $4|2-4| 4$.

4. Cruz C., Luna G., Stabridis O., Coello C., Morales R. Gasto Catastrófico en Salud. Ingreso por tipo de gastos en servicios de salud en México. Bienestar y Política Social. Universidad Iberoamericana. 2006. 6:5I-73.

5. Acuerdo por el que se emiten las Reglas de Operación del Programa Seguro Médico para una Nueva Generación, para el ejercicio fiscal 2008. 3 I de marzo del 2008. [sitio en internet]. México. [consultado 2009 octubre 18]. Disponible en: http://www.ropsa.net/ropsa/.

6. CONEVAL. [. Lineamientos Generales para la Evaluación de los Programas Federales de la Administración Pública Federal .Diario Oficial de la Federación. México. Viernes 30 de marzo de 2007.[sitio en internet] México [consultado 2009 octubre 10] Disponible en: http//www.coneval. gob.mx/contenido/eva_mon/36lpdf.) (acceso 02 ene.2010.

7. Secretaría de Salud. Si Calidad. Manual para la acreditación y garantía de calidad en establecimientos para la prestación de servicios de salud. [sitio en internet] México. [consultado 2009 octubre 10]. Disponible en: http://www.calidad.salud.gob.mx/calidad/acred.html.

8. Jasso GL. Taquipnea transitoria. En Neonatología práctica. 7a edición. México. El Manual Moderno. 2008: 256.

9. Jasso GL. ¿Habrá en el futuro un mayor número acumulado de individuos con secuelas neurológicas por haber nacido prematuros. Bol Med Hosp Infant (Méx). 2008; 65: 327-330.

10. López-Candiani C, Santamaría-Arza C, Macías-Avilés A, Cruz-Galicia J. Dificultad respiratoria por deficiencia de surfactante en un hospital público de tercer nivel sin maternidad . Factores asociados a mortalidad. Bol Med Hosp Infan (Mex) 2010;67: 98-107.

II. Champion V, Durrmeyer X, Dassieu G. Short-term respiratory outcome of late preterm newborn in a center of level III. Arch Pediatr. 2010 ; 17:19-25. Epub 2009 Nov II.

12. Blackmon LR; Barfield WD Stark; AR. Hospital Neonatal Services in the United States: Variation in Definitions, Criteria, and Regulatory Status, 2008. J Perinatol. 2009;29:788-94.

13. Jasso GL. Medicamentos en Neonatología. En: Jasso GL. Neonatología práctica. 7a edición. México. El Manual Moderno. 2008.403-408.

14. Demirel N, Bas AY, Zenciroglu A. Bronchopulmonary dysplasia in very low birth weight infants. Indian J Pediatr. 2009; 76:695-8.

15. Giannakopoulou C, Hatzidaki E, Korakaki E, Christodoulaki M, Margari KM, Mamoulakis. Comparative randomized study: administration of natural and synthetic surfactant to premature newborns with respiratory distress syndrome. Pediatr Int. 2002; 44:1 17-2I. 